Pacific Journal of Mathematics

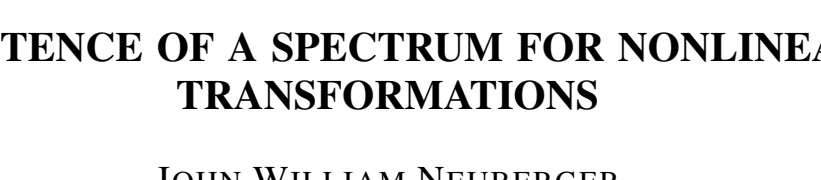




\section{EXISTENCE OF A SPECTRUM FOR NONLINEAR TRANSFORMATIONS}

\section{J. W. Neuberger}

Denote by $S$ a complex (nondegenerate) Banach space. Suppose that $T$ is a transformation from a subset of $S$ to $S$. A complex number $\lambda$ is said to be in the resolvent of $T$ if $(\lambda I-T)^{-1}$ exists, has domain $S$ and is Fréchet differentiable (i.e., if $p$ is in $S$ there is a unique continuous linear transformation $F=\left[(\lambda I-T)^{-1}\right]^{\prime}(p)$ from $S$ to $S$ so that

$$
\left.\lim _{q \rightarrow p}\|q-p\|^{-1}\left\|(\lambda I-T)^{-1} q-(\lambda I-T)^{-1} p-F(q-p)\right\|=0\right)
$$

and locally Lipschitzean everywhere on $S$. A complex number is said to be in the spectrum of $T$ if it is not in the resolvent of $T$.

Suppose in addition that the domain of $T$ contains an open subset of $S$ on which $T$ is Lipschitzean.

Theorem. T has a (nonempty) spectrum.

If $T$ is a continuous linear transformation from $S$ to $S$, then the notion of resolvent and spectrum given here coincides with the usual one ([1], p. 209, for example). Such a transformation $T$ is, of course, Lipschitzean on all of $S$ and hence the above theorem gives as a corollary the familiar result that a continuous linear transformation on a complex Banach space has a spectrum.

The set of all complex numbers is denoted by $C$.

Lemma. Suppose that $d>0, p$ is in $S, Q$ is a transformation from a subset of $S$ to $S, D$ is an open set containing $p$ which is a subset of the domain $Q, Q$ is Lipschitzean on $D$ and $(I-c Q)^{-1}$ exists and has domain $S$ if $c$ is in $C$ and $|c|<d$. Then,

$$
\lim _{c \rightarrow 0}(I-c Q)^{-1} p=p .
$$

Proof. Denote by $M$ a positive number so that $\|Q r-Q s\| \leqq$ $M\|r-s\|$ if $r$ and $s$ are in $D$. Suppose $\varepsilon>0$. Denote by $\delta$ a number so that $0<\delta<\min (\varepsilon, 1 / 2)$ and $\{q \in S:\|q-p\| \leqq \delta\}$ is a subset of $D$. Denote by $\delta^{\prime}$ a positive number so that $\delta^{\prime}(\max (M,\|Q p\|))<\delta / 2$. Denote by $c$ a member of $C$ so that $|c|<\min \left(\delta^{\prime}, d\right)$. Denote $(I-c Q)^{-1} p$ by $q$, denote $p$ by $q_{0}$ and $p+c Q q_{n-1}$ by $q_{n}, n=1,2, \cdots$.

Then, $\left\|q_{1}-q_{0}\right\|=\left\|p+c Q q_{0}-q_{0}\right\|=|c|\left\|Q q_{0}\right\|<\delta / 2$. Suppose that $k$ is a positive integer so that

$$
\left\|q_{m}-q_{m-1}\right\|<(\delta / 2)^{m}, m=1,2, \cdots, k .
$$


Then $\left\|q_{m}-p\right\| \leqq \sum_{j=0}^{m-1}\left\|q_{j+1}-q_{j}\right\| \leqq \sum_{j=0}^{m-1}(\delta / 2)^{j+1}<\delta, m=0,1, \cdots, k$ and hence

$$
\begin{aligned}
& \left\|q_{k+1}-q_{k}\right\|=\left\|c Q q_{k}-c Q q_{k-1}\right\| \\
& \quad \leqq|c| M\left\|q_{k}-q_{k-1}\right\| \\
& \quad \leqq|c| M(\delta / 2)^{k} \leqq(\delta / 2)^{k+1}
\end{aligned}
$$

Hence $\left\|q_{n}-q_{n-1}\right\| \leqq(\delta / 2)^{n}, n=1,2, \ldots$ and therefore $q_{1}, q_{2}, \cdots$ converges to a point $r$ of $S$. Note that $\left\|q_{n+1}-p\right\| \leqq \sum_{j=0}^{n}(\delta / 2)^{j+1}<\delta, n=$ $1,2, \cdots$ so that $\|r-p\| \leqq \delta$ and hence $r$ is in $D$. But $\|r-(p+c Q r)\|=$ $\left\|\left(r-q_{n+1}\right)+\left(p+c Q q_{n}\right)-(p+c Q r)\right\| \leqq\left\|r-q_{n+1}\right\|+|c|\left\|Q q_{n}-Q r\right\| \leqq$ $\left\|r-q_{n+1}\right\|+|c| M\left\|q_{n}-r\right\| \rightarrow 0$ as $n \rightarrow \infty$. Hence $r=p+c Q r$, i.e., $(I-c Q) r=p$, i.e., $r=(I-c Q)^{-1} p=q$. Hence, $\left\|(I-c Q)^{-1} p-p\right\| \leqq$ $\delta<\varepsilon$. This proves the lemma.

Proof of theorem. Suppose the statement of the theorem is false. Then $T$ has an inverse since if not, 0 would be in the spectrum of $T$. Denote by $D$ an open set on which $T$ is defined and is Lipschitzean. Denote by $p$ a point of $D$ different from $-T(0)$.

Define $f(\lambda)$ to be $(\lambda I-T)^{-1} p$ for all $\lambda$ in $C$. Suppose $b$ is in $C$. If $q$ is in $S$ and different from $p$ denote

$$
\left.(1 /\|q-p\|)\left\{[b I-T)^{-1} q-(b I-T)^{-1} p\right]-\left[(b I-T)^{-1}\right]^{\prime}(p)(q-p)\right\}
$$

by $L(q)$. Denote by $L(p)$ the zero element of $S$ and note that $\lim _{p \rightarrow p} L(q)=L(p)$ since $(b I-T)^{-1}$ is Fréchet differentiable at $p$. Denote $(b I-T)^{-1}$ by $Q$. If $\lambda$ is in $C$, then

$$
(\lambda I-T)=\left[I-(b-\lambda)(b I-T)^{-1}\right](b I-T)
$$

and, since both $(\lambda I-T)^{-1}$ and $(b I-T)^{-1}$ exist and have domain $S$, it follows that $\left[I-(b-\lambda)(b I-T)^{-1}\right]^{-1}=[I-(b-\lambda) Q]^{-1}$ has the same properties and $(\lambda I-T)^{-1}=Q[I-(b-\lambda) Q]^{-1}$.

Hence, if $\lambda$ is in $C$,

$$
\begin{aligned}
f(\lambda)-f(b)= & Q[I-(b-\lambda) Q]^{-1} p-Q p \\
= & Q^{\prime}(p)\left[[I-(b-\lambda) Q]^{-1} p-p\right] \\
& +\left\|[I-(b-\lambda) Q]^{-1} p-p\right\| L\left([I-(b-\lambda) Q]^{-1} p\right) .
\end{aligned}
$$

But $[I-(b-\lambda) Q]^{-1} p-p=(b-\lambda) Q[I-(b-\lambda) Q]^{-1} p$ so

$$
\begin{aligned}
&(\lambda-b)^{-1}[f(\lambda)-f(b)] \\
&=-Q^{\prime}(p) Q[I-(b-\lambda) Q]^{-1} p \\
&+(|b-\lambda| /(\lambda-b))\left\|Q[I-(b-\lambda) Q]^{-1} p\right\| \\
& \times L\left([I-(b-\lambda) Q]^{-1} p\right) \rightarrow-Q^{\prime}(p) Q p
\end{aligned}
$$

as $\lambda \rightarrow b$ since $\lim _{\lambda \rightarrow b}[I-(b-\lambda) Q]^{-1} p=p$. Hence, 


$$
f^{\prime}(b)=-\left[(b I-T)^{-1}\right]^{\prime}(p)(b I-T)^{-1} p .
$$

Now $\lim _{c \rightarrow 0}(I-c T)^{-1} p=p$. Denote by $\delta$ a positive number so that if $|c| \leqq \delta$, then $\left\|(I-c T)^{-1} p\right\| \leqq\|p\|+1$. Then if $\lambda$ is in $C$ and $|\lambda| \geqq 1 / \delta,\|f(\lambda)\|=\left\|(\lambda I-T)^{-1} p\right\|=|1 / \lambda|\left\|(I-(1 / \lambda) T)^{-1} p\right\| \leqq$ $\delta(\|p\|+1)$. Hence $f$ is bounded. So, by Liouville's theorem ([1], p. 129, for example), $f$ is constant, i.e., there is a point $q$ in $S$ such that if $\lambda$ is in $C,(\lambda I-T)^{-1} p=f(\lambda)=q$, and so $\lambda q=p+T q$. Hence it must be that $q=0$, i.e., $p=-T(0)$, a contradiction. This establishes the theorem.

The author considers it likely that the statement of the theorem is true if the condition (in the definition of resolvent) that $(\lambda I-T)^{-1}$ be locally Lipschitzean is dropped.

\section{REFERENCE}

1. K. Yosida, Functional analysis, Academic Press, New York, 1965.

Received December 12, 1968. The author is an Alfred P. Sloan Research Fellow. 



\section{PACIFIC JOURNAL OF MATHEMATICS}

\section{EDITORS}

H. ROYDEN

Stanford University

Stanford, California

Richard Pierce

University of Washington

Seattle, Washington 98105
J. DUGUNDJI

Department of Mathematics

University of Southern California

Los Angeles, California 90007

BASIL GORDON

University of California

Los Angeles, California 90024

\section{ASSOCIATE EDITORS}
E. F. BECKENBACH
B. H. NEUMANN
F. WOLF
K. YosHIDA

\section{SUPPORTING INSTITUTIONS}

UNIVERSITY OF BRITISH COLUMBIA

CALIFORNIA INSTITUTE OF TECHNOLOGY

UNIVERSITY OF CALIFORNIA

MONTANA STATE UNIVERSITY

UNIVERSITY OF NEVADA

NEW MEXICO STATE UNIVERSITY

OREGON STATE UNIVERSITY

UNIVERSITY OF OREGON

OSAKA UNIVERSITY

UNIVERSITY OF SOUTHERN CALIFORNIA
STANFORD UNIVERSITY

UNIVERSITY OF TOKYO

UNIVERSITY OF UTAH

WASHINGTON STATE UNIVERSITY

UNIVERSITY OF WASHINGTON

*

AMERICAN MATHEMATICAL SOCIETY CHEVRON RESEARCH CORPORATION TRW SYSTEMS

NAVAL WEAPONS CENTER 


\section{Pacific Journal of Mathematics}

\section{Vol. 31, No. $1 \quad$ November, 1969}

James Burton Ax, Injective endomorphisms of varieties and schemes........

Richard Hindman Bouldin, A generalization of the Weinstein-Aronszajn

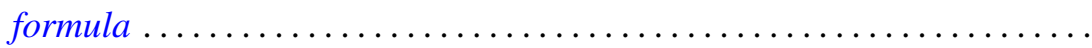

John Martin Chadam, The asymptotic behavior of the Klein-Gordon equation with external potential. II ...............................

Rina Hadass, On the zeros of the solutions of the differential equation

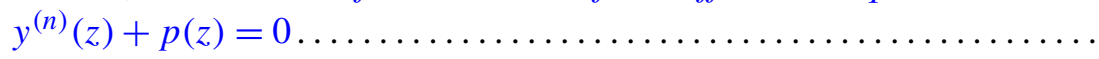

John Sollion Hsia, Integral equivalence of vectors over local modular lattices. II .............................................

Robert Hughes, Boundary behavior of random valued heat polynomial

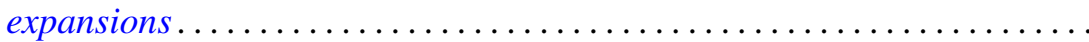

Surender Kumar Jain, Saad H. Mohamed and Surjeet Singh, Rings in which every right ideal is quasi-injective .........................

T. Kawata, On the inversion formula for the characteristic function .........

Erwin Kleinfeld, On right alternative rings without proper right ideals......

Robert Leroy Kruse and David Thomas Price, On the subring structure of

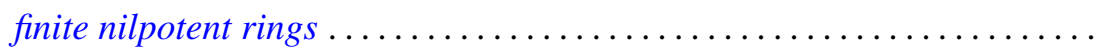

Marvin David Marcus and Stephen J. Pierce, Symmetric positive definite multilinear functionals with a given automorphism. .

William Schumacher Massey, Pontryagin squares in the Thom space of a bundle...

William Schumacher Massey, Proof of a conjecture of Whitney ...

John William Neuberger, Existence of a spectrum for nonlinear transformations

Stephen E. Newman, Measure algebras on idempotent semigroups ...

$\mathrm{K}$. Chandrasekhara Rao, Matrix transformations of some sequence spaces

Robert Bruce Schneider, Some theorems in Fourier analysis on symmetric

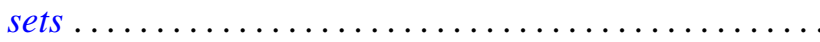

Ulrich F. K. Schoenwaelder, Centralizers of abelian, normal subgroups of hypercyclic groups...

Jerrold Norman Siegel, $G$-spaces, $H$-spaces and $W$-spaces

Robert Irving Soare, Cohesive sets and recursively enumerable Dedekind cuts...

Kwok-Wai Tam, Isometries of certain function spaces .... . .

Awadhesh Kumar Tiwary, Injective hulls of semi-simple modules over regular rings ....

Eldon Jon Vought, Concerning continua not separated by any nonaposyndetic subcontinuum .................... 